\title{
Randomized Trial of Phosphodiesterase Inhibitors Versus Catecholamines in Patients With Acutely Decompensated Heart Failure
}

\author{
Akio Kawamura, MD; Tsutomu Yoshikawa, MD; Toshiyuki Takahashi, MD; \\ Takeharu Hayashi, MD; Eiichi Takahashi, MD; Toshihisa Anzai, MD; \\ Toru Sato, MD; Satoshi Ogawa, MD
}

\begin{abstract}
Increased neurohormone and cytokine concentrations are associated with adverse outcome in patients with congestive heart failure, so minimizing these increases may improve outcome, even in the acute phase of decompensated heart failure. The present study was designed to test the hypothesis that phosphodiesterase inhibitors, but not catecholamines, could favorably affect neurohormone and cytokine profiles in patients with acutely decompensated heart failure. Twenty-nine patients underwent monitoring using a Swan-Ganz catheter and were randomly allocated to receive phosphodiesterase inhibitors (PDEI group, $n=19$ ) or catecholamines (CA group, $\mathrm{n}=10$ ). Pulmonary capillary wedge pressure decreased significantly in both groups and cardiac output showed a slight, but not statistically significant increase, in both groups. There was a significant decrease in plasma brain natriuretic peptide concentration in the PDEI group, but not in the CA group, whereas plasma interleukin-6 concentration increased in the CA group, but not in the PDEI group. Phosphodiesterase inhibitors favorably affect neurohormone and cytokine concentrations in patients with acutely decompensated heart failure. (Jpn Circ J 2001; 65: 858-862)
\end{abstract}

Key Words: Brain natriuretic peptide; Cytokine; Interleukin-6; Neurohormones

$\mathbf{S}$ ynthetic catecholamines (CA), including dopamine and dobutamine, have been traditionally used for inotropic support in the treatment of acutely decompensated heart failure. Recently, phosphodiesterase inhibitors (PDEI), inotropic agents with vasodilatory effects, have emerged as new therapeutic agents for acutely decompensated heart failure. Catecholamines have potent inotropic and vasoconstrictor effects, which are essential pharmacologic profiles in patients with cardiogenic shock, but they potentially increase cardiac oxygen consumption, resulting in an acceleration of myocardial damage. In addition, congestive heart failure is characterized by $\beta$-adrenergic receptor desensitization, limiting the adrenergic responsiveness to inotropic stimuli1,2 In contrast, PDEI do not increase cardiac oxygen consumption, and they preserve intracellular cyclic-AMP concentrations by inhibiting its breakdown?

It is well known that neurohormonal activation, including the sympatho-adrenal system, renin-angiotensin system, arginine-vasopressin, endothelin, and natriuretic peptide, is associated with adverse clinical outcome in patients with congestive heart failure ${ }^{4-8}$ and recently, plasma adrenomedullin concentration was shown to be associated with mortality in such patients? On the other hand, there is emerging evidence that cytokines contribute to the abnormal pathophysiology that leads to congestive

(Received February 19, 2001; revised manuscript received June 15, 2001; accepted July 4, 2001)

Cardiology Division, Department of Medicine, Keio University School of Medicine, Tokyo, Japan

Mailing address: Tsutomu Yoshikawa, MD, Cardiology Division, Department of Medicine, Keio University School of Medicine, 35 Shinanomachi, Shinjuku-ku, Tokyo 160-8582, Japan. E-mail: tyoshi @ mc.med.keio.ac.jp heart failure, including cardiac remodeling, hypertrophy and contractile dysfunction. Transgenic mice overexpressing tumor necrosis factora exhibit a form of cardiac dilatation and contractile dysfunction that closely resembles human dilated cardiomyopathy ${ }^{10,11}$ and the plasma concentration of interleukin- 6 can predict the life expectancy for patients with congestive heart failure! ${ }^{2}$ Phosphodiesterase inhibitors suppressed cytokine production in in vitro experiments, $13-17$ whereas CA may increase production of cytokines! ${ }^{18,19} \mathrm{We}$ hypothesized that these agents have divergent effects on cytokine production in the clinical setting and in this study, we investigated the effect of PDEI and CA on the hemodynamics and neurohormone and cytokine levels in patients with acutely decompensated heart failure.

\section{Methods}

\section{Study Population}

A total of 29 patients with acutely decompensated heart failure, who were eligible for randomization to either $\mathrm{CA}$ or PDEI, were examined. They were admitted to hospital from July 1997 through February 2000 and included patients showing clinical evidence of congestive heart failure; that is, systemic blood pressure ranging from 90 $\mathrm{mmHg}$ to $160 \mathrm{mmHg}$ and pulmonary venous congestion on chest roentgenogram. Patients with systolic blood pressure less than $90 \mathrm{mmHg}$ or more than $160 \mathrm{mmHg}$ were excluded. Invasive hemodynamic monitoring using a Swan-Ganz catheter was suggested, but not mandatory. The mean age was $64 \pm 3$ (range: $31-90$ ) years. Twenty-one patients were male.

Patients were initially treated using conventional therapy, including intravenous furosemide, nitrates, or carperitide. 
Table 1 Baseline Characteristics of the Study Population

\begin{tabular}{lcc}
\hline \hline & PDEI group $(n=19)$ & CA group $(n=10)$ \\
\hline Age (years) & $68 \pm 3$ & $58 \pm 5$ \\
Malelfemale & $13 / 6$ & $8 / 2$ \\
Etiology of heart failure & & \\
$\quad$ Primary myocardial disease & $5(26 \%)$ & $4(40 \%)$ \\
Coronary artery disease & $9(47 \%)$ & $2(20 \%)$ \\
Hypertension & $3(16 \%)$ & $2(20 \%)$ \\
Valvular heart disease & $2(11 \%)$ & $1(10 \%)$ \\
Congenital heart disease & $0(0 \%)$ & $1(10 \%)$ \\
Heart rate $($ beats $/$ min) & $86 \pm 4$ & $90 \pm 4$ \\
Systolic blood pressure $\left(\mathrm{mmHg}^{\prime}\right)$ & $128 \pm 3$ & $127 \pm 7$ \\
PCW (mmH) & $24 \pm 2$ & $26 \pm 3$ \\
Cardiac output $\left(L \cdot\right.$ min $\left.^{-1} \cdot \mathrm{m}^{-2}\right)$ & $2.4 \pm 0.2$ & $2.2 \pm 0.3$ \\
Carperitide & $10(56 \%)$ & $2(20 \%)$ \\
Nitrates & $4(21 \%)$ & $5(50 \%)$ \\
\hline
\end{tabular}

PDEI, phosphodiesterase inhibitor group; CA, catecholamine group; PCW, pulmonary capillary wedge pressure.

Table 2 Baseline Neurohormone and Cytokine Concentrations

\begin{tabular}{|c|c|c|c|c|}
\hline & \multicolumn{2}{|c|}{ PDEI group $(n=19)$} & \multicolumn{2}{|c|}{ CA group $(n=10)$} \\
\hline & Before & After & Before & After \\
\hline$N E(\mathrm{pg} / \mathrm{ml})$ & $972 \pm 124$ & $876 \pm 138$ & $772 \pm 109$ & $648 \pm 179$ \\
\hline$E(p g / m l)$ & $87 \pm 17$ & $38 \pm 8 * *$ & $141 \pm 38$ & $47 \pm 12 *$ \\
\hline$D A(p g / m l)$ & $39 \pm 8$ & $34 \pm 9$ & $25 \pm 7$ & $10,964 \pm 6,744$ \\
\hline$A R C(\mathrm{pg} / \mathrm{ml})$ & $55 \pm 23$ & $99 \pm 29$ & $26 \pm 14$ & $51 \pm 32$ \\
\hline Ang II $(\mathrm{pg} / \mathrm{ml})$ & $20 \pm 6$ & $29 \pm 8$ & $29 \pm 18$ & $14 \pm 3$ \\
\hline$A L D(p g / m l)$ & $93 \pm 16$ & $101 \pm 33$ & $65 \pm 11$ & $59 \pm 11$ \\
\hline$A V P(\mathrm{pg} / \mathrm{ml})$ & $12.4 \pm 4.6$ & $6.2 \pm 1.6$ & $6.6 \pm 2.3$ & $4.4 \pm 1.1$ \\
\hline$A N P(p g / m l)$ & $227 \pm 54$ & $434 \pm 78$ & $168 \pm 45$ & $261 \pm 107$ \\
\hline$B N P(p g / m l)$ & $918 \pm 195$ & $409 \pm 102 * *$ & $607 \pm 121$ & $753 \pm 303$ \\
\hline$E T-1(\mathrm{pg} / \mathrm{ml})$ & $5.15 \pm 0.47$ & $4.41 \pm 0.53$ & $7.06 \pm 1.99$ & $3.53 \pm 0.48$ \\
\hline$A M(f m o l / m l)$ & $39 \pm 6$ & $35 \pm 6$ & $58 \pm 25$ & $60 \pm 25$ \\
\hline$I L-6(\mathrm{pg} / \mathrm{ml})$ & $22 \pm 4$ & $31 \pm 5$ & $53 \pm 45$ & $93 \pm 56^{*}$ \\
\hline
\end{tabular}

PDEI, phosphodiesterase inhibitor group; CA, catecholamine group; NE, norepinephrine; E, epinephrine; DA, dopamine; ARC, activated renin concentration; Ang II, angiotensin II; ALD, aldosterone; AVP, arginine-vasopressin; ANP, atrial natriuretic peptide; BNP, brain natriuretic peptide; ET-1, endothelin-1; AM, adrenomedullin; IL-6, interleukin-6. * $<<0.05$, **p<0.01 before vs after.

In the 19 patients who underwent right heart catheterization, the mean pulmonary capillary wedge pressure was $25 \pm 2 \mathrm{mmHg}$, and cardiac output was $2.4 \pm 0.2 \mathrm{~L} \cdot \mathrm{min}^{-1} \cdot \mathrm{m}^{-2}$. All of the subjects gave informed consent. Critically ill patients who failed to give such consent were not enrolled.

\section{Study Protocol}

Patients were randomized to the CA or PDEI group, initially $1: 3$, but later $1: 1$ for each group because the number of patients who were allocated to CA group was insufficient to compare with the PDEI group. Coadministration of nitrates, nicardipine, carperitide, and furosemide was permitted, if patients were stable on them before entry. All inotropic agents, including digitalis glycosides, were discontinued before entry. Patients were allowed to receive either PDEI or CA at the discretion of their attending physicians. For the PDEI group, olprinone was administered in 14 patients $\left(0.12 \pm 0.01 \mu \mathrm{g} \cdot \mathrm{kg}^{-1} \cdot \mathrm{min}^{-1}\right)$, milrinone in $4\left(0.50 \mu \mathrm{g} \cdot \mathrm{kg}^{-1} \cdot \mathrm{min}^{-1}\right)$, and amrinone in $1\left(5.0 \mu \mathrm{g} \cdot \mathrm{kg}^{-1}\right.$. $\left.\min ^{-1}\right)$. For the CA group, dopamine was administered in 4 $\left(2.0 \pm 0.4 \mu \mathrm{g} \cdot \mathrm{kg}^{-1} \cdot \mathrm{min}^{-1}\right)$ and dobutamine in 6 patients $\left(4.0 \pm 1.0 \mu \mathrm{g} \cdot \mathrm{kg}^{-1} \cdot \mathrm{min}^{-1}\right)$. Patients were observed for at least $24 \mathrm{~h}$. Other treatment for heart failure were not altered during the study, except for bolus injections of furosemide. Blood samples were obtained before and $24 \mathrm{~h}$ after administration of the drugs.

\section{Measurement of Neurohormones and Cytokines}

Plasma levels of neurohormones, including norepinephrine, epinephrine, dopamine (high performance liquid chromatography), renin, angiotensin II, aldosterone, arginine-vasopressin, atrial and brain natriuretic peptides (ANP and BNP), endothelin-1, and adrenomedullin (radioimmunoassay), were determined, as were the plasma levels of cytokines (ie, tumor necrosis factora (enzyme-linked immunosorbent assay), interleukin-6 (chemiluminescent enzyme immunoassay), and interferon- $\gamma$ (enzyme immunoassay)).

\section{Statistical Analysis}

Data are expressed as the mean \pm SEM. Comparisons between groups were performed using nonpaired t-tests. Changes within the same groups were assessed using paired t-tests. Statistical significance was considered to be present when $\mathrm{p}<0.05$.

\section{Results}

Nineteen patients were randomized to the PDEI group, and 10 to the catecholamine group. Table 1 shows the baseline characteristics of the groups. Patients allocated to the PDEI group tended to be older than those allocated to the CA group, although this difference was not statistically significant. There was no overall difference in gender or 

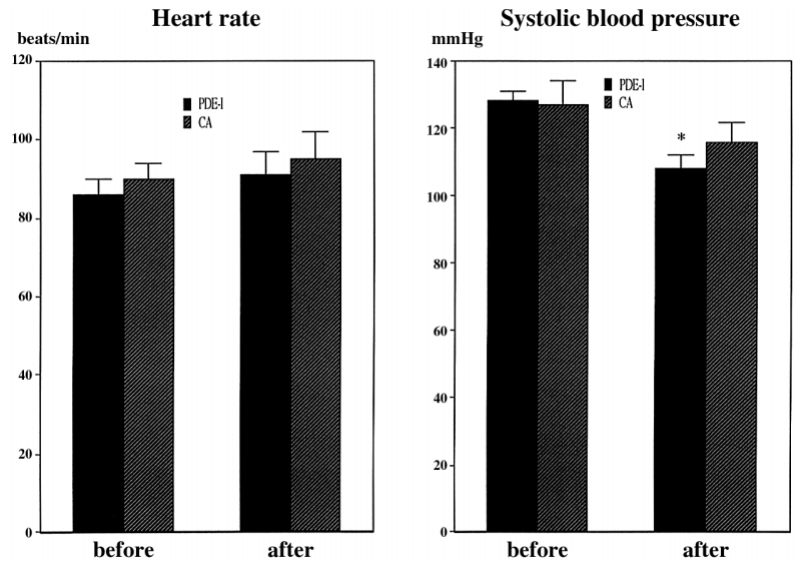

Fig 1. Heart rate and systolic blood pressure before and after administration of phosphodiesterase inhibitor (PDEI) or catecholamines (CA). Heart rate tended to increase in both groups, but this change was not statistically significant. Systolic blood pressure decreased substantially in the PDEI group, but not in the CA group. *p<0.0001 before vs after.

the etiology of heart failure between the 2 groups. Baseline hemodynamic data including heart rate, systolic blood pressure, pulmonary capillary wedge pressure, and cardiac output were also comparable between the groups. Concomitant intravenous use of vasodilators, including carperitide and nitrates, was also comparable between the groups. None of the patients received intravenous nicardipine.

Table 2 shows the plasma neurohormone levels and cytokine levels, which were similar between the groups. Plasma tumor necrosis factora and interferon-y were not detectable in this study population.

During the observation period, fluid intake did not differ between the 2 groups (CA group, 1,328 $\pm 139 \mathrm{ml} /$ day; PDEI group, $1,288 \pm 126 \mathrm{ml} /$ day), but urine volume was greater in the CA group than in the PDEI group $(3,632 \pm 410 \mathrm{ml} /$ day vs $1,887 \pm 410 \mathrm{ml} /$ day, $\mathrm{p}=0.0001)$. Two patients experienced adverse events during the observation period. One of them, who received olprinone, developed hypotension and was withdrawn from the study $7 \mathrm{~h}$ after administration of the drug. The other patient, who received dobutamine, developed non-sustained ventricular tachycardia of 7 consecutive beats, but was able to continue the study drug for $24 \mathrm{~h}$.

Fig 1 shows the hemodynamic variables before and after administration of each study drug. Heart rate tended to be increased in both the PDEI (from $86 \pm 4$ to $91 \pm 6$ beats/min) and CA groups (from $90 \pm 4$ to $95 \pm 7$ beats/min), although the difference was not statistically significant. Systolic blood pressure decreased significantly in the PDEI group (from $128 \pm 3$ to $108 \pm 4 \mathrm{mmHg}, \mathrm{p}<0.0001$ ), but not in the CA group (from $127 \pm 7$ to $116 \pm 6 \mathrm{mmHg}$, NS). The double product, calculated by multiplying heart rate and systolic blood pressure, was significantly decreased in the PDEI group (from $11,052 \pm 559$ to $9,670 \pm 480, p<0.01$ ), but not in the CA group (from $11,463 \pm 881$ to $11,236 \pm 1,374, \mathrm{NS}$ ). Pulmonary capillary wedge pressure was significantly decreased in the PDEI group (from $24 \pm 2$ to $13 \pm 2 \mathrm{mmHg}$, $\mathrm{p}<0.005$ ), but only slightly decreased in the CA group (from $26 \pm 3$ to $19 \pm 3 \mathrm{mmHg}, \mathrm{p}<0.05$ ); cardiac output tended to be increased in both the PDEI (from $2.6 \pm 0.3$ to $3.3 \pm 0.4$ $\mathrm{L} \cdot \mathrm{min}^{-1} \cdot \mathrm{m}^{-2}$ ) and the CA groups (from $2.2 \pm 0.3$ to $2.5 \pm 0.2$ $\mathrm{L} \cdot \mathrm{min}^{-1} \cdot \mathrm{m}^{-2}$ ), but this change was not statistically significant (Fig 2). In the CA group, pulmonary capillary wedge
Pulmonary capillary wedge pressure mmHg
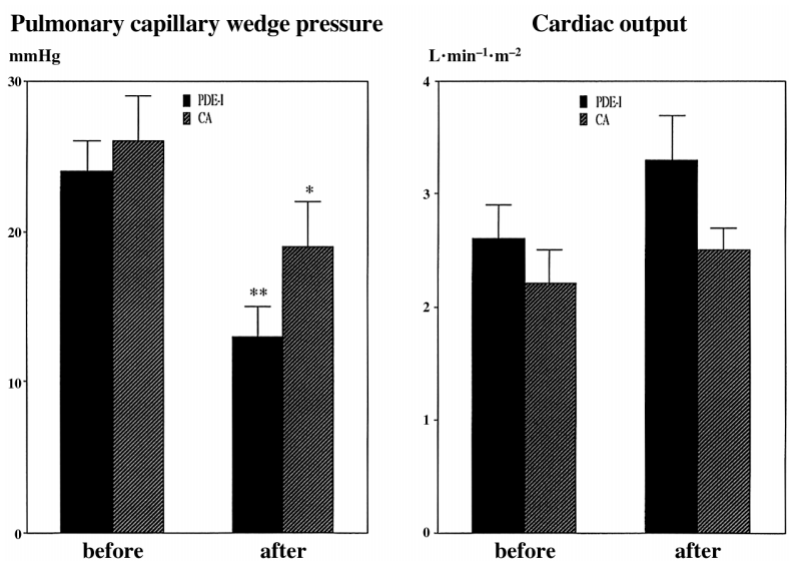

Fig 2. Pulmonary capillary wedge pressure decreased more significantly in the phosphodiesterase inhibitor (PDEI) group than in the catecholamine (CA) group. Cardiac output showed a slight, but not statistically significant increase in both groups. ${ }^{*} \mathrm{p}<0.05$ before vs after; $* * \mathrm{p}<0.005$ before vs after.

pressure tended to be decreased more in patients who received dopamine than those who received dobutamine, whereas cardiac output tended to be increased more in patients who received dobutamine than those who received dopamine. However, because the number of patients was quite limited, there was no statistically significant difference. In the PDEI group, the trend in the hemodynamic changes was similar among the 3 drugs, although the number was too small to detect statistical significance.

Table 2 shows that the changes in the plasma neurohormone and cytokine concentrations before and after administration of a PDEI or CA. Plasma BNP concentrations were significantly decreased in the PDEI, but not in the CA group; plasma interleukin-6 concentrations did not change in the PDEI group, but increased in the CA group; plasma epinephrine concentrations were decreased in both the PDEI and CA groups. The other neurohormones did not change significantly during the observation period. There was no correlation between the decrease in plasma BNP and the decrease in systolic blood pressure or pulmonary capillary wedge pressure nor was there a correlation between the change in plasma interleukin- 6 levels and the decrease in systolic blood pressure or pulmonary capillary wedge pressure.

\section{Discussion}

\section{Hemodynamic Variables}

Heart rate tended to increase after administration of drugs in both the PDEI and CA groups, although this difference was not statistically significant. However, systolic blood pressure was significantly lowered in the PDEI group, but not in the CA group, which suggests that the double product, reflecting myocardial oxygen consumption, was decreased significantly by the use of PDEIs. Consistent with this finding, there was a dramatic reduction in pulmonary capillary wedge pressure in the PDEI group, whereas there was only a slight decrease in the CA group. Cardiac output showed a slight, but not statistically significant, increase in both groups. These findings suggest that PDEIs, but not CAs, improve hemodynamics and have a favorable effect on cardiac oxygen consumption. These differences, which are consistent with a previous study, ${ }^{20}$ may have a signifi- 
cant impact on the clinical management of acutely decompensated heart failure.

The trend in the hemodynamic changes did not differ between the 3 drugs in the PDEI group, although previous studies have reported some differences ${ }^{21,22}$ In the present study, olprinone was the main PDEI and it is difficult to determine the potential differences of the other drugs because we used them in quite small numbers of patients.

\section{Brain Natriuretic Peptide Concentrations}

Plasma BNP concentrations were decreased in the PDEI group, but not in the CA group and the ANP concentrations did not change in either group. There are independent mechanisms that regulate ANP and BNP concentrations. Brain natriuretic peptide is transcriptionally regulated and constitutively secreted, whereas atrial natriuretic peptide is not. ${ }^{3}$ Furthermore, ANP concentrations are generally elevated in the setting of atrial overload, whereas BNP concentrations are more closely related to ventricular overload 24

In the PDEI group, the decrease in BNP concentration is most likely to be mediated by alleviation of ventricular overload, because there is no current evidence that PDEIs have a direct effect on BNP secretion. In the CA group, BNP concentrations were not decreased, perhaps because ventricular overload was not sufficiently decreased. If a greater dose had been used, the plasma level would have been lowered. Alternatively, in vitro experiments have shown that norepinephrine induces fetal gene expression, including that of ANP and BNP, in cultured neonatal rat cardiomyocytes in association with the development of cardiac hypertrophy, ${ }^{23}$ which suggests that the effects of a modest decrease in ventricular overload on lowering the natriuretic peptide concentrations elicited by $\mathrm{CA}$ may be offset by $\mathrm{CA}$-induced increases in natriuretic peptide production.

\section{Plasma Interleukin-6 Concentrations}

Papanicolaou et al showed that plasma interleukin-6 concentrations were increased during treadmill exercise in humans and that this increase correlated closely with plasma norepinephrine and epinephrine concentrations 18 Tsutamoto et al demonstrated that plasma norepinephrine concentration was a positive predictor and $\beta$-blocker use a negative predictor of plasma interleukin- 6 concentration $!^{2}$ These observations suggest that administration of CA induces production of cytokines, including interleukin-6. In fact, chronic $\beta$-adrenergic receptor stimulation using isoproterenol has been shown to induce proinflammatory cytokine production in cardiomyocytes ${ }^{25}$ By contrast, PDEIs, including amrinone, pimobendan, and vesnarinone, have been shown to decrease tumor necrosis factora and interleukin- 6 production by peripheral blood mononuclear cells stimulated with lipopolysaccharide in vitro? 26 In vivo administration of pimobendan also decreased the tissue content of interleukin-6, as well as tumor necrosis factora and interleukin- $\beta$, in mice infected with encephalomyocarditis virus. ${ }^{27}$ These observations suggest that PDEIs suppress the production of cytokines including interleukin6. It is possible that the plasma interleukin-6 level was affected by hemodynamic changes, because the pulmonary capillary wedge pressure was decreased more in the PDEI group than in the CA group. However, we could not detect any correlation between the plasma interleukin-6 levels and the decreases in systolic blood pressure or pulmonary capillary wedge pressure.

In the present study, the plasma interleukin- 6 concentration did not change during administration of PDEIs, whereas this cytokine actually increased in concentration during administration of CAs. Interleukin-6 had a concentration-dependent negative inotropic effect in isolated strips of myocardial tissue obtained from guinea pig that was blocked by an inhibitor of NO synthase 28 Double transgenic mice overexpressing both interleukin-6 and its receptor develop cardiac hypertrophy. ${ }^{29}$ One clinical study has demonstrated that the plasma concentration of interleukin6 predicts long-term survival in patients with congestive heart failure ${ }^{12}$ and so PDEI may be a useful therapeutic modality in terms of cardioprotection, even in the setting of acutely decompensated heart failure.

Plasma epinephrine concentrations were decreased in both study groups and may have been caused by negative feedback of endogenous CAs in the presence of synthetic CAs or cardiotonic agents, or may simply reflect hemodynamic improvement in both groups.

\section{Summary}

We compared the effects of PDEIs and CAs on hemodynamics and the concentrations of plasma neurohormones and cytokines in patients with acutely decompensated heart failure. The double product was decreased by PDEIs, but not by CAs. Pulmonary capillary wedge pressure was significantly reduced by both PDEIs and CAs. Cardiac output tended to increase, but this change was not statistically significant. Plasma BNP concentrations were decreased by PDEIs, but not by CAs. Plasma interleukin-6 concentrations were increased by CAs, but not by PDEIs. Phosphodiesterase inhibitors appear to be preferable to CAs for patients with acutely decompensated heart failure in terms of neuroendocrine activation and cytokine secretion. Such therapy could favorably affect the in-hospital course, because previous findings have shown that attenuation of neuroendocrine activation and cytokine production is associated with a favorable long-term outcome in patients with chronic heart failure.

\section{References}

1. Bristow MR, Ginsburg R, Minobe W, Cubicciotti RS, Sageman WS, Lurie K, et al: Decreased catecholamine sensitivity and beta-adrenergic-receptor density in failing human hearts. N Engl J Med 1982; 307: 205-211

2. Yoshikawa T, Handa S, Suzuki M, Nagami K: Abnormalities in sympathoneuronal regulation are localized to failing myocardium in rabbit heart. J Am Coll Cardiol 1994; 24: 210-215

3. Feldman MD, Copelas L, Gwathmey JK, Phillips P, Warren SE, Shoen FJ, et al: Deficient production of cyclic AMP: Pharmacologic evidence of an important cause of contractile dysfunction in patients with end-stage heart failure. Circulation 1987; 75: 331-339

4. Cohn JN, Levine B, Olivari MT, Garberg V, Lura D, Francis GS, et al: Plasma norepinephrine as a guide to the prognosis in patients with chronic congestive heart failure. N Engl J Med 1984; 311: 819-823

5. The CONSENSUS Study Group: Hormones regulating cardiovascular function in patients with severe congestive heart failure and their relation to mortality. Circulation 1990; 82: 1730-1736

6. Rouleau J-L, Packer M, Moyé L, de Champlain J, Bichet D, Klein M, et al: Prognostic value of neurohumoral activation in patients with an acute myocardial infarction: Effect of captopril. J Am Coll Cardiol 1994; 24: $583-591$

7. Wei CM, Lerman A, Rodeheffer RJ, McGregor CG, Brandt RR, Wright S, et al: Endothelin in human heart failure. Circulation 1994; 89: $1580-1586$

8. Tsutamoto T, Wada A, Maeda K, Hisanaga T, Maeda Y, Fukai D, et al: Attenuation of compensation of endogenous cardiac natriuretic peptide concentration in patients with chronic symptomatic left 
ventricular dysfunction. Circulation 1997; 96: 509-516

9. Richards AM, Doughty R, Nicholls MG, MacMahon S, Sharpe N, Murphy J, et al: Plasma N-terminal pro-brain natriuretic peptide and adrenomedullin: Prognostic utility and prediction of benefit from carvedilol in chronic ischemic left ventricular dysfunction. J Am Coll Cardiol 2001; 37: 1781-1787

10. Kubota T, McTiernan CF, Frye CS, Slawson SE, Lemster BH, Koretsky AP, et al: Dilated cardiomyopathy in transgenic mice with cardiac-specific overexpression of tumor necrosis factora. Circ Res 1997; 81: 627-635

11. Bryant D, Becker L, Richardson J, Shelton J, Franco F, Peshock R, et al: Cardiac failure in transgenic mice with myocardial expression of tumor necrosis factora. Circulation 1998; 97: 1375-1381

12. Tsutamoto T, Hisanaga T, Wada A, Maeda K, Ohnishi M, Fukai D, et al: Interleukin-6 spillover in the peripheral circulation increases with the severity of heart failure, and the high plasma level of interleukin-6 is an important prognostic predictor in patients with congestive heart failure. J Am Coll Cardiol 1998; 31: 391-398

13. Giroir BP, Beutler B: Effect of amrinone on tumor necrosis factor production in endotoxin shock. Circ Shock 1992; 36: 200-207

14. Endres S, Sinha B, Fulle H-J: Amrinone suppresses the synthesis of tumor necrosis factora in human mononuclear cells. Shock 1994; 1: $377-380$

15. Matsumori A, Shioi T, Yamada T, Matsui S, Sasayama S: Vesnarinone, a new inotropic agent, inhibits cytokine production by stimulated human blood from patients with heart failure. Circulation 1994; 89: $955-958$

16. Seldon PM, Barnes PJ, Meja K, Giembycz MA: Suppression of lipopolysaccharide-induced tumor necrosis factora generation from human peripheral blood monocytes by inhibitors of phosphodiesterase 4: Interaction with stimulants of adenylyl cyclase. Mol Pharmacol 1995; 48: 747-757

17. Bergman MR, Holycross BJ: Pharmacological modulation of myocardial tumor necrosis factor alpha production by phosphodiesterase inhibitors. J Pharmacol Exp Ther 1996; 279: 247-254

18. Papanicolaou DA, Tsigos PC, Kalogeras KT, Wilder R, Gold PW, Deuster PA, et al: Exercise stimulates interleukin-6 secretion: Inhibition by glucocorticoids and correlation with catecholamines. Am J Physiol 1996; 271: E601-E605

19. Barth W, Deten A, Bauer M, Reinohs M, Leicht M, Zimmer H:
Differential remodeling of the left and right heart after norepinephrine treatment in rats: Studies on cytokines and collagen. $J$ Mol Cell Cardiol 2000; 32: 273-284

20. Tanaka K, Takano T, Seino Y: Effects of intravenous amrinone on heart failure complicated by acute myocardial infarction: Comparative study with dopamine and dobutamine. Jpn Circ J 1986; 50: 652-658

21. Iribe G, Yamada H, Matsunaga A, Yoshimura N: Effects of the phosphodiesterase III inhibitors olprinone, milrinone, and amrinone on hepatosplanchnic oxygen metabolism. Crit Care Med 2000; 28: $743-$ 748

22. Hirabayashi Y, Igarashi T, Saitoh K, Fukuda H, Suzuki H, Shimizu $\mathrm{R}$ : Comparison of the effects of amrinone, milrinone and olprinone in reversing bupivacaine-induced cardiovascular depression. Acta Anaethesiol Scand 2000; 44: 1128-1133

23. Nakagawa O, Ogawa Y, Itoh H, Suga S, Komatsu Y, Kishimoto I, et al: Rapid transcriptional activation and early mRNA turnover of brain natriuretic peptide in cardiocyte hypertrophy: Evidence for brain natriuretic peptide as an 'emergency' cardiac hormones against ventricular overload. J Clin Invest 1995; 96: 1280-1287

24. Yoshimura M, Yasue H, Okumura K, Ogawa H, Jougasaki M, Mukoyama M, et al: Different secretion patterns of atrial natiuretic peptide and brain natriuretic peptide in patients with congestive heart failure. Circulation 1993; 87: 464-469

25. Murray DR, Prabhu SD, Chandrasekar B: Chronic $\beta$-adrenergic stimulation induces myocardial proinflammatory cytokine expression. Circulation 2000; 101: 2338-2341

26. Matsumori A, Ono K, Sato Y, Shioi T, Nose Y, Sasayama S: Differential modulation of cytokine production by drugs: Implications for therapy in heart failure. J Mol Cell Cardiol 1996; 28: 2491-2499

27. Iwasaki A, Matsumori A, Yamada T, Shioi T, Wang W, Ono K, et al: Pimobendan inhibits the production of proinflammatory cytokines and gene expression of inducible nitric oxide synthase in a murine model of viral myocarditis. J Am Coll Cardiol 1999; 33: 1400-1407

28. Finkel MS, Oddis CV, Jacob TD, Watkins SC, Hattler BG, Simmons RL: Negative inotropic effects of cytokines on the heart mediated by nitric oxide. Science 1992; 257: 387-389

29. Hirota H, Yoshida K, Kishimoto T, Taga T: Continuous activation of gp130, a signal-transducing receptor component for interleukin 6related cytokines, causes myocardial hypertrophy in mice. Proc Natl Acad Sci USA 1995; 92: 4862-4866 